\title{
Solid-Phase Extraction of Several Phthalate Esters from Environmental Water Samples on a Column Packed with Polytetrafluoroethylene Turnings
}

\author{
Yaqi CaI, Guibin JIANG, ${ }^{\dagger}$ and Jingfu LIU \\ Key Laboratory of Environmental Chemistry and Ecotoxicology, Research Center for Eco-Environmental \\ Sciences, Chinese Academy of Sciences, P. O. Box 2871, Beijing, 100085, China
}

\begin{abstract}
A method for the determination of several phthalate esters in water samples using solid-phase extraction coupled to highperformance liquid chromatography was developed. A polytetrafluoroethylene turnings packed column was used as a SPE adsorbent material. The analytes were sorbed on polytetrafluoroethylene turnings, from which they were eluted by a small amount of acetonitrile, followed by a RP-HPLC-UV analysis. Detection limits $(3 \sigma)$ of 4.7, 3.1, 3.6, 4.3, and 5.8 ng $\mathrm{mL}^{-1}$ for di- $n$-butyl-phthalate, di-cyclohexyl-phthalate, di- $n$-octyl-phthalate, di- $n$-nonyl-phthalate and di-iso-decylphthalate, respectively, were achieved. Acceptable recovery results $(92.1-127.5 \%)$ were obtained on five phthalate esters spiked samples.
\end{abstract}

(Received February 24, 2003; Accepted August 18, 2003)

\section{Introduction}

In recent years, great attention has been paid to some environmental chemicals which may exert some adverse effects on animals and humans. Phthalate esters are widely regarded as such chemicals, and their existences in the environment are almost ubiquitous. ${ }^{1,2}$ Because of the carcinogenicity and estrogenicity of these compounds, ${ }^{3,4}$ the determination of these compounds in environmental samples is urgently required for environmental impact and risk assessment. Unfortunately, the very low concentration level of phthalate esters and the complex matrix of many environmental samples makes it very difficult for a direct determination of these compounds; therefore, a simple, efficient, reliable and rapid method for sample preparation is still demanded.

Because of possessing the advantages of high recovery, a short analysis time, a high enrichment factor, low cost and low consumption of organic solvents, solid-phase extraction (SPE) based on the use of different types of adsorbents, such as $\mathrm{C}_{18}$ and PS-DVB polymer, has been applied to the determination of phthalate esters in environmental samples by gas and liquid chromatography. ${ }^{5-7}$ It would appear that the most successful SPE of phthalate esters are generally acquired by using various hydrophobic materials as adsorbents. In view of the fact that polytetrafluoroethylene (PTFE) possesses a very strong hydrophobic property and that PTFE experimental containers can readily adsorb neutral hydrophobic compounds on their surfaces, ${ }^{8-10}$ it can be inferred that suitable forms of PTFE materials perhaps have great potential as an effective adsorbent. Indeed, knotted reactors (KR), made from properly knotted long PTFE tubes have been used as sorbent surfaces of chelates of metal ions in the preconcentration and determination of metal

$\dagger$ To whom correspondence should be addressed.

E-mail: gbjiang@mail.rcees.ac.cn ions. ${ }^{11,12}$ SPE mini-columns packed with PTFE turnings have also been applied for the preconcentration of $\mathrm{Cu}^{2+}$ and $\mathrm{Cr}(\mathrm{VI})$ before their determinations by atomic absorption spectrometry. ${ }^{13,14}$ Recently, research work on the in situ extraction and preconcentraction of PCBs and PAHs from aqueous samples using PTFE tubing has been reported..$^{15}$ Because of possessing a much larger surface area than PTFE tubing, PTFE turnings would be a much more effective SPE adsorbent of hydrophobic organic compounds. Up to now, no report about the SPE of organic compounds using PTFE turnings as an adsorbent has appeared.

In this work, the potential of PTFE turnings as the matrix for SPE of trace phthalate esters from aqueous samples was carefully explored for the first time. By driving the aqueous sample solution to pass through a PTFE turnings packed column, the analytes were retained on the PTFE turnings in the column. Then, the retained analytes were eluted with acetonitrile, followed by a RP-HPLC-UV analysis. The parameters affecting the analytical performance, including the flow rate of a sample solution, the volume of the sample and the eluent, were studied. The recovery of SPE using PTFE turnings was relatively low but acceptable for the extraction of di- $n$ butyl-phthalate (DBP), di-cyclohexyl-phthalate (DCHP), di- $n$ octyl-phthalate (DOP), di- $n$-nonyl-phthalate (DNP) and di-isodecyl-phthalate (DDP) from aqueous solution. Clear advantages of PTFE turnings as a SPE adsorbent include easy availability and durability. The potential applications of proposed method were also examined.

\section{Experimental}

Reagents and samples

All reagents used were of analytical-reagent grade, and purified water by a Milli-Q system was used throughout the experiments. DBP, DCHP, DOP and DNP were purchased 
from Acros Organics (NJ, USA). DDP was purchased from Shanghai Chemicals Corporation, Shanghai, China. LC-grade acetonitrile and methanol were obtained from Scharlace Chemie SA, Barcelona, Spain. Sodium chloride was guarantee grade reagent (Beijing Chemicals Corporation, Beijing, China). Standard stock solutions (1 $\left.\mathrm{mg} \mathrm{mL}^{-1}\right)$ containing these five phthalate esters were prepared in methanol and stored at $4^{\circ} \mathrm{C}$. Working solutions were prepared daily by appropriate dilution of the stock solutions. A tap water sample was collected from a water tap in our laboratory; a river-water sample was collected in the Jingmi Canal. The water samples were filtered through a Millipore cellulose membrane with a pore size $0.45 \mu \mathrm{m}$ immediately after sampling, and kept in a glass containers at $4^{\circ} \mathrm{C}$.

\section{Instrumentation}

The HPLC instrument used included a SCL-10Avp system controller (Shimadzu, Japan), a LC-10Atvp pump (Shimadzu, Japan), and a SPD-M10Avp diode array detector (DAD, Shimadzu, Japan) set at $226 \mathrm{~nm}$ wavelength for detection. The separations were performed on an Agilent Zorbax Eclipse XDB$\mathrm{C}_{8}$ column $(150 \times 4.6 \mathrm{~mm}$, particle size $5 \mu \mathrm{m})$. The mobile phase was a mixture of acetonitrile and water $(97+3, v+v)$ and its flow rate was set at $0.4 \mathrm{~mL} \mathrm{~min}^{-1}$. A personal computer equipped with a Class-VP Workstation (Shimadzu, Japan) was used to process chromatographic data. Under these chromatographic conditions, baseline separation could be obtained within 17 min for five phthalate esters.

\section{SPE column and preconcentration system}

The column used was a short empty HPLC column $(5.2 \mathrm{~cm} \times$ $4.0 \mathrm{~mm}$ ) made of polypropylene. The SPE sorbent material was $800 \mathrm{mg}$ of PTFE turnings with a mean width of $0.1 \mathrm{~mm}$, which were mechanically produced by a lathe. In order to reduce the levels of organic and inorganic contaminants, the PTFE turnings were washed successively with a thorough volume of $1 \mathrm{~mol} \mathrm{~L}^{-1}$ nitric acid, ethanol and water. By using a dry packing method, $800 \mathrm{mg}$ PTFE turnings were packed in the above-mentioned short empty HPLC column. A small amount of quartz wool was placed at both ends of the column to keep the PTFE turnings in place. Upon completion of column preparation, the column was connected to a piston minipump (Milton Roy Company, Chicago, USA) with PTFE tubes (i.d. $0.5 \mathrm{~mm}$ ). Prior to use, the entire assembly was carefully rinsed with a sufficient amount of purified water.

\section{SPE procedure}

The PTFE turnings-packed SPE column was conditioned by the passage of $5 \mathrm{~mL}$ of acetonitrile and $10 \mathrm{~mL}$ of Milli-Q purified water. A piston pump was applied to drive acetonitrile and Milli-Q purified water through the SPE column. Upon completion of the column conditioning, a known volume of water sample or an analyte spiked water sample was delivered through the SPE column at a flow rate of $7.6 \mathrm{~mL} \mathrm{~min}^{-1}$. When the sample solution had passed through the SPE column, the column was subsequently washed with $5 \mathrm{~mL}$ of Milli-Q purified water. Then, the analytes retained on the column were eluted by $10 \mathrm{~mL}$ of acetonitrile. Finally, an aliquot of $20 \mu \mathrm{L}$ was injected into the HPLC system for analysis. After every SPE extraction, the PTFE turnings-packed column was again washed with another $5 \mathrm{~mL}$ of acetonitrile and $10 \mathrm{~mL}$ of Milli-Q purified water.

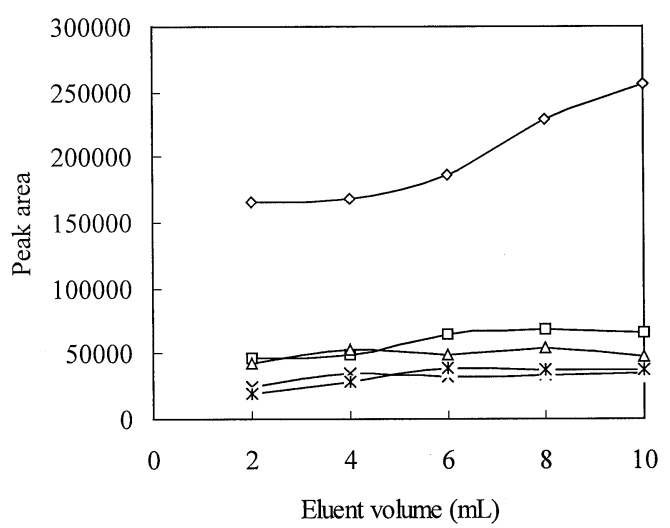

Fig. 1 Effect of the eluent acetonitrile volume on the peak area of phthalates. $\diamond$, DBP; $\square$, DCHP; $\triangle$, DOP; $\times$, DNP; $*$, DDP. Solution: $200 \mathrm{~mL}, 100 \mathrm{ng} \mathrm{mL}^{-1}$. See text for other experimental conditions.

\section{Results and Discussion}

\section{Optimization of desorption conditions}

It was found that an appropriate amount of methanol or acetonitrile was an effective eluent for the five analytes retained on the PTFE turnings-packed column. Considering that acetonitrile had already been selected as the main composition of the mobile phase, we adopted acetonitrile as an eluent in our experiments. To find the required volume of acetonitrile to elute all five analytes from the PTFE turnings-packed column, eluent volumes of up to $10 \mathrm{~mL}$ were investigated; the experimental results are given in Fig. 1. As can be seen, for the extraction of DCHP, DOP, DNP and DDP, the increases of the peak areas were hardly observed when the volume of acetonitrile was in the range of $2-10 \mathrm{~mL}$. For the extraction of DBP, with an increase in the amount of acetonitrile, about a $50 \%$ increase of the peak area was observed. Therefore, $10 \mathrm{~mL}$ of acetonitrile was adopted as the eluent throughout the experiments. Because carryover is very harmful to the next extraction, it was also examined in our studies. Despite no carryover being observed, to obtain a quantitative analytical result for the next extraction, in our experiment, the column was washed further with another $5 \mathrm{~mL}$ of acetonitrile and $10 \mathrm{~mL}$ of Milli-Q purified water at the end of each extraction.

\section{Effect of the flow rate of sample solutions}

In the SPE system, the flow rate of the sample solution is one of the most important parameters, which not only affects the recoveries of the analytes, but also controls the time of analysis. It was found that flow rates of up to $7.6 \mathrm{~mL} \mathrm{~min}^{-1}$ (the maximum flow rate of our pump) for water sample loading on the column had no effect on the recoveries of five analytes. Therefore, $7.6 \mathrm{~mL} \mathrm{~min}{ }^{-1}$ was chosen as the flow rate of sample solutions in our experiments.

\section{Effect of the volumes of sample solutions}

In order to investigate the effect of the volumes of sample solutions, different volumes of purified water were spiked with five analytes at different concentration levels. Following the experimental procedure, $10 \mathrm{~mL}$ of acetonitrile eluate was obtained; $20 \mu \mathrm{L}$ of acetonitrile eluate was injected into the HPLC system for the determination. By using acetonitrile standard solutions of five analytes, an external calibration curve could be acquired, and then the concentrations of five analytes 
Table 1 Extraction recoveries obtained for five phthalates at different volumes of sample solution

\begin{tabular}{lcccc}
\hline \multirow{4}{*}{ Compound } & \multicolumn{4}{c}{ Recovery $^{\mathrm{a}} \%$} \\
& $200 \mathrm{~mL}_{\text {of }}$ & $200 \mathrm{~mL}^{-1}$ & $500 \mathrm{~mL}$ of & $500 \mathrm{~mL}$ of \\
& $100 \mathrm{ng} \mathrm{mL}^{-1}$ & $500 \mathrm{ng} \mathrm{mL}^{-1}$ & $100 \mathrm{ng} \mathrm{mL}^{-1}$ & $40 \mathrm{ng} \mathrm{mL}^{-1}$ \\
\hline DBP & 83.2 & 72.8 & 66.5 & 67.4 \\
DCHP & 74.9 & 66.3 & 67.5 & 62.5 \\
DOP & 65.2 & 64.2 & 69.2 & 68.4 \\
DNP & 60.4 & 68.0 & 66.0 & 68.2 \\
DDP & 67.1 & 64.7 & 62.9 & 65.0 \\
\hline
\end{tabular}

a. Mean for three determinations.

Table 2 Slopes, correlation coefficients and detection limits

\begin{tabular}{lccc}
\hline Compound & $\begin{array}{c}\text { Slope } \\
\left(1 / \mathrm{ng} \mathrm{mL}^{-1}\right)\end{array}$ & $\begin{array}{c}\text { Correlation } \\
\text { coefficient }\end{array}$ & $\begin{array}{c}\mathrm{LOD}^{\mathrm{a}} / \\
\mathrm{ng} \mathrm{mL}^{-1}\end{array}$ \\
\hline DBP & 8916 & 0.992 & 4.7 \\
DCHP & 8403 & 0.999 & 3.1 \\
DOP & 7854 & 0.987 & 3.6 \\
DNP & 6921 & 0.993 & 4.3 \\
DDP & 6744 & 0.995 & 5.8 \\
\hline
\end{tabular}

a. Calculated as $3 \sigma$ of five replicate runs of procedure blanks.

Table 3 Recoveries of five target analytes spiked real water samples

\begin{tabular}{ccc}
\hline Water sample & Added/ng $\mathrm{mL}^{-1}$ & Recovery ${ }^{\mathrm{a}}, \%$ \\
\hline Tap water & & \\
DBP & 100 & $103.8 \pm 1.9$ \\
DCHP & 100 & $104.6 \pm 2.1$ \\
DOP & 100 & $97.8 \pm 2.1$ \\
DNP & 100 & $104.5 \pm 2.8$ \\
DDP & 100 & $104.4 \pm 2.3$ \\
River water & & \\
DBP & 100 & $101.4 \pm 6.9$ \\
DCHP & 100 & $114.6 \pm 2.2$ \\
DOP & 100 & $127.5 \pm 9.2$ \\
DNP & 100 & $106.7 \pm 3.6$ \\
DDP & 100 & $92.1 \pm 6.7$ \\
\hline
\end{tabular}

a. Mean and standard deviation for five determinations.

in the eluate were obtained. Finally, the recoveries of five analytes at different conditions could be obtained by comparing the concentrations of five analytes in the eluate with the spiked concentration levels. The effects of the sample volumes on the recoveries of five analytes are given in Table 1. From Table 1, we can know that lower recoveries $(62.9-83.2 \%)$ that were obtained for all five analytes studied; no great difference existed between the recoveries at $200 \mathrm{~mL}$ and $500 \mathrm{~mL}$. Although the lower recoveries were not what we expected, as long as the experimental parameters, such as the sample volume, eluent volume and the flow rate were carefully controlled, reliable and acceptable analytical results could also be obtained. In analyses of environmental water samples, $500 \mathrm{~mL}$ was selected as the sample volume.

\section{Analytical performance and application}

Under the selected conditions, the analytical performance of the proposed method was examined. There was a linear correlation between the peak area and the concentration from 10

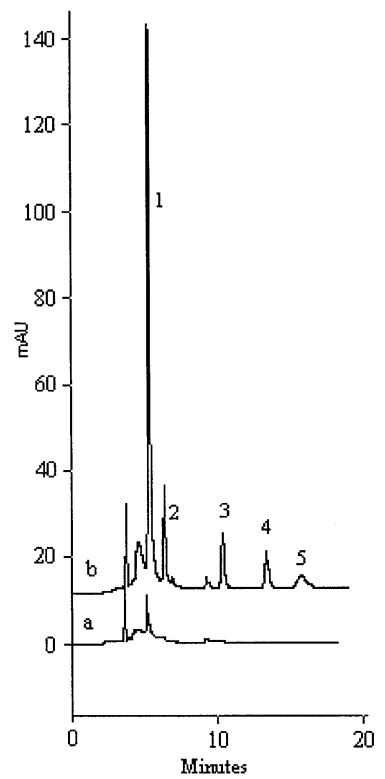

Fig. 2 SPE-HPLC-UV chromatograms of tap-water sample spiked with $100 \mathrm{ng} \mathrm{mL}^{-1}$ of each phthalate. (a) Tap water sample, (b) tap water sample spiked with $100 \mathrm{ng} \mathrm{mL}^{-1}$ of each phthalate. 1, DBP; 2, DCHP; 3, DOP; 4, DNP; 5, DDP. See text for other experimental conditions.

to $200 \mathrm{ng} \mathrm{mL}^{-1}$ for five phthalates. The slopes of the calibration curves and the detection limits of five alanytes calculated as $3 \sigma$ of five determinations are listed in Table 2.

The proposed method had also been applied to analyze two real water samples. No DBP, DCHP, DOP, DNP or DDP was found in the tap-water and river-water samples. Recovery tests were carried out with spiked standard phthalate mixtures to the tested water samples; the results are presented in Table 3. It is observed that acceptable recovery results $(92.1-127.5 \%)$ were obtained for DBP, DCHP, DOP, DNP and DDP. Chromatograms of the tap-water sample and its spiked standard solution are shown in Fig. 2.

\section{Acknowledgements}

This work was jointly supported by the National Natural Science Foundation of China, the National High Technology Project and the Chinese Academy of Sciences (KZCX2-410).

\section{References}

1. I. Steiner, L. Scharf, F. Fiala, and J. Washuttl, Food Add. Contam., 1998, 15, 812.

2. M. Castillo, A. Oubina, and D. Barcelo, Environ. Sci. Technol., 1998, 32, 225.

3. C. A. Harris, P. Henttu, M. G. Parker, and J. P. Sumpter, Environ Health Perspect, 1997, 105, 802.

4. L. H. Keith, "Environmental Endocrine Disruptors-A Handbook of Property Data", 1997, Wiley-Interscience, New York.

5. S. Jobling, T. Reynolds, R. White, M. G. Parker, and J. P. Sumpter, Environ Health Perspect, 1995, 103, 582.

6. M. Castillo, A. Oubina, and D. Barcelo, Environ. Sci. Technol., 1998, 32, 2180. 
7. S. Jara, C. Lysebo, T. Greinbrokk, and E. Lundanes, Anal. Chim. Acta, 2000, 407, 165.

8. S. C. Lung, Y. Yanagisawa, T. E. Ford, and J. D. Spengler, Chemosphere, 2000, 41, 1857.

9. R. Doong, S. Chang, and Y. Sun, J. Chromatogr. Sci., 2000, 38, 528 .

10. L. Nardi, Am. Lab., 2002, 34, 30.

11. S. C. Nielsen and E. H. Hansen, Anal. Chim. Acta, 1998, $366,165$.
12. E. Ivanova, K. Benkhedda, and F. Adams, J. Anal. At. Spectrom., 1998, 13, 527.

13. A. N. Anthemidis, G. A. Zachariadis, and J. A. Stratis, Talanta, 2001, 54, 935.

14. A. N. Anthemidis, G. A. Zachariadis, J.-S. Kougoulis, and J. A. Stratis, Talanta, 2002, 57, 15 .

15. X.-F. Li, W. R. Cullen, and K. J. Reimer, Analyst, 2002, 127,730 . 